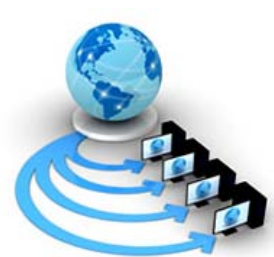

Volume 8, No. 9, November-December 2017

International Journal of Advanced Research in Computer Science

RESEARCH PAPER

Available Online at www.ijarcs.info

\title{
PROPOSING MMABOAR: MIND MAP APPLICATION BASED ON AUGMENTED REALITY
}

\author{
Aina Sharma \\ Department of Computer Science \& Engg \\ Sri Sai College of Engg and Technology, \\ Manawala (Amritsar) Punjab (India)
}

\author{
Rimmy Chuchra \\ Department of Computer Science \& Engg ${ }^{1}$ \\ Sri Sai College of Engg and Technology \\ , Manawala (Amritsar) Punjab \\ (India)
}

\begin{abstract}
This paper discusses about the field of augmented reality which covers its wide area as an example applications based on AR and different types of technologies used in AR as like tracking technology, display technology and interaction technologies. This paper gives a new idea based on mobile AR (Augmented Reality) application that is named as MMABOAR (Mind Map App based on Augmented Reality) whose main purpose is read all mind vibrations or mind thoughts. The main motive to design such kind of app is to provide a way to communicate with mentally disabled persons and utilize their past experiences and knowledge in current running projects of research. By utilizing such kind of knowledge or intelligence they can also individually contribute for discovering new India. The working of this new designed mind app is based on the way of touching of that app icon. Once that disable person touch that particular app then it will sense or read(or record or save) the complete knowledge in your phone memory backup. And once the backup is created then you will use that past knowledge or experiences anywhere, anytime in future. This paper also discusses about some new techniques suited or uses by the developers in mobile AR. Hence, this new designed app may provide us a new type of learning platform (NTOLP) through mentally disabled persons or mentally retarded persons.Inshort, this mobile learning helps to create a real learning environment, which will greatly improve the efficiency or effectiveness of learning.
\end{abstract}

Keywords: Augmented Reality, Learning Platform, Mobile learning, Mind Map Application, programming, software development and AR Toolkit.

\section{INTRODUCTION}

The study of augmented reality tells about the cyber physical system visualization and interaction challenges in multiple domains including medicine, construction, advertising, manufacturing and gaming technology. The purpose to utilize this concept is to merge physical world with the virtual world[5].Several different types of technologies [10] as like AR interaction technologies, AR display technologies and AR tracking technologies as shown in figure 1,2 and 3 [14]:

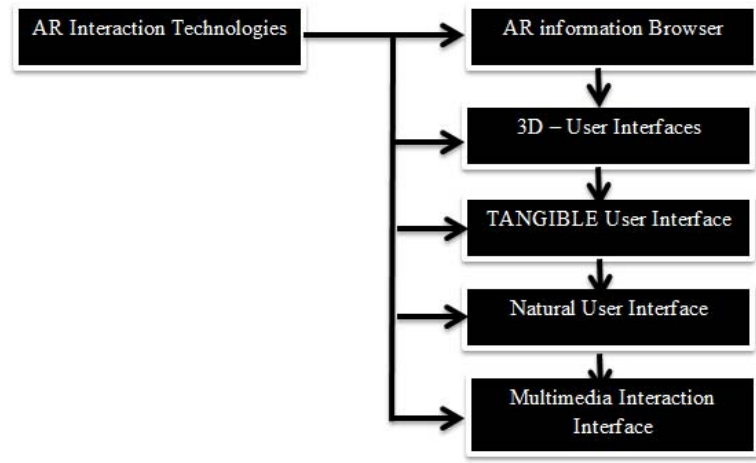

Figure 1: Types of AR Interaction Technologies [14].

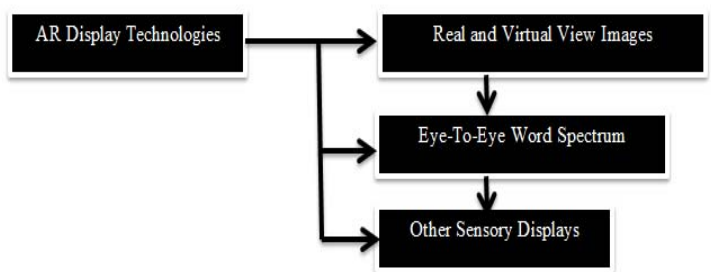

Figure 2: Types of AR Display Technologies [14].

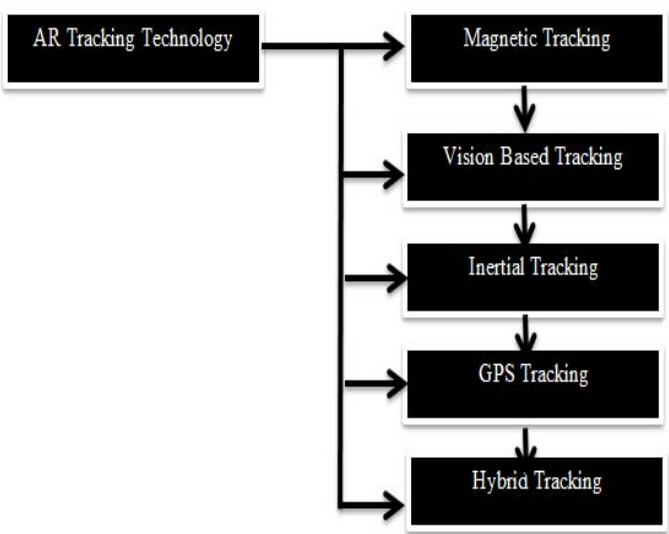

Figure 3: Different types of AR Tracking Technologies [14]. 
Uses the integrated approach of AR(Augmented Reality), VR (Virtual Reality) and MR (Mixed Reality) is to collect 3D Experience [7][9]in several different fields as an example health, public safety and especially in gaming field [18]. AR devices analyze the surrounding of real world and display different images to different eyes from different points of view[3]. In Addition, AR devices also provides various different types of information as like information related to whether, Tracking information through GPS(Global Positioning System) and more importantly they provide real time information[6][8][17] that may be in the form of several different ways as an example image,text,audio,video and some other visual aids or virtual enhancements that are directly or indirectly related with real world objects[2]. Ultimately, the main task of AR developers is to convert AR world to the real world. Both of these realities are not exactly same but are very close to each other. The study of these different types of reality provides a new platform of learning form the real world environment is called "ReflexiveLearning"[12].In other words, authors may say this new platform of learning is basically helps to promote learning[11] by putting some efforts on physical content that ultimately provides new related content over physical objects [13].That's the main reason of its more popularity and said by authors in their literature study. The list of AR (Augmented Reality) based applications is given below:-

$\begin{array}{cc}\checkmark & \text { Computer Tomography. } \\ \checkmark & \text { Ultrasound Imaging. } \\ \checkmark & \text { Video Games [1]. } \\ \checkmark & \text { Military Training [8] }- \text { that may include } \\ & \text { machine vision, object recognition and } \\ & \text { gesture recognition [2]. } \\ \checkmark & \text { Driving Simulations [4]. } \\ \checkmark & \text { Flight and Surgery Training [9]. } \\ \checkmark & \text { Virtual Museum Exhibitions [7]. } \\ \checkmark & \text { Learning and Computing Environment, Gas, } \\ & \text { Oil, Tourism and Marketing etc [2]. } \\ & \text { Some upcoming Augmented reality based } \\ \text { apps are Pokeman Go, Ink Hunter, } & \text { Wallame, Star Chart, Google Translate, } \\ \text { Wikitude World Browser, Yelp } & \text { Spyglasses, } \\ \text { Monocle,theodolite } & \text { Augmented Car Finder and Google Sky } \\ \text { Map used for Navigation [4][15]. }\end{array}$

MMPABOAR( Mind Map Phone Application based on Augmented Reality) whose main purpose is to utilize mentally disabled person's experience, knowledge and their intelligence in current running research projects. The working of this new designed application is based on the simple touch icon. The main function of this mind map based application is to read and record the mind vibrations or thoughts present in specific person mind. (Mentally disabled person). The main significance to design a new methodology is utilize mentally disabled persons knowledge, past experiences and intelligence for discovering new India.Hence, once the mind file is created, then users can save this back up in phone memory and computer system and further utilize in different research projects. The major benefit to utilize this concept of Augmented Reality is to collect or gain more efficient mobile experience [1] and provides more interactive multimedia objects interaction experience in the era of education that ultimately helps to change the phase of learning in class room [2]. In this way, as named by authors this next interface step of augmented reality provides new world of entertainment as well as massive computing [3]. Hence, Augmented Reality planners provide a new method of learning from the surrounding and collect different types of information from different aspects[16].

\section{RESEARCH DESIGN}

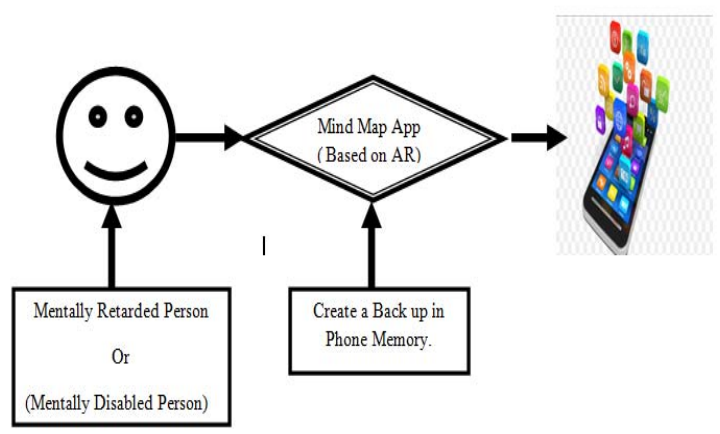

Figure.4: Communication between Mentally Disabled Person with Mind Map Application Based on Augmented Reality.

\section{CONCLUSION}

Different types of technologies uses in AR (augmented reality) are discussed in this paper. This new designed mind map app based on augmented reality helps to provide a mind back up of any mentally retarded person or any disabled person. The main benefit to design such kind of app is to utilize the past experiences and knowledge of mentally disabled persons as like scientists or researchers in the current research scenarios. This type of new enhancements in AR will then respond to new market opportunities that are yet need to be explored. The next generation mobile devices anticipate a horizon of adoption of AR as a mainstream technology. In short, AR provides that much potential direction for upcoming research (further research or future research).

\section{FUTURE SCOPE}

In future, this work will extend for developing mind thought models. These newly developed models may also help to gives the description about how human brain logic actually works and how thoughts are mapped in brain on the time of information processing in brain. In short, by utilizing this idea the structure of thoughts can be clearlymentioned and even showeddiagrammatically. This is a new world of thought generation and exploration.

\section{REFERENCES}

[1] TikuNi shi, Joshi Sneha,”Augmented Reality”, International journal of advance research in computer science and management studies, Vol.3,Issue 2, and Febuary 2015.

[2] Aozuma T. Ronald,” A survey of Augmented Reality”, In presence:-Teleperators\& Virtual EVS 6, August 1997. 
[3] Jules white and Douglas Schmidt, "Applications of Augmented REALITY", Civil and Environmental Engineering- IEEE, 2014.

[4] Sha Ling, "Research proposal on reviewing augmented reality applications for supporting ageing population", Volume 3, ELSEVIER, 2015.D.O.I:- https:// doi.org/10.10161 K. promfg.2015.07.132.

[5] Mark Aunel Schnabel and Xingu Wang,” From Virtuality to Reality and back", University of Sydney, Australia.

[6] Brognia. A and Avizzanas, "Technological approach for cultural heritage: Augmented Reality, PERCRO, ITALY.

[7] F.Liarokapis\&S.Sylaiou," An interactive visualization interface for virtual museums", theeuro graphics association 2004.

[8] Veronika Long, “Augmented Reality Applications for Real Estate”, Vienna, May 2013.

[9] Leon Van Berloabd Kristion A. Helmholt, "See to Be: Augmented Reality on the Construction side", International Conference on Construction applications of Virtual Reality, November 2009.

[10] Mohd Nihra Haruzuan Mohamad Said, Norazlina BintiI smail,"Overview of open source AR Toolkit”, International Malaysian Educational Technology Convention.

[11] Steve Chi-Yin Yuen,” Augmented Reality - An Overview and five directions for Augmented Reality in education", Journal of Educational Technology Development and exchange Vol.4 Issue 1.
[12] Simone Mora \& Alessandro Boron, "Playing with mobile Augmented Reality for fostering informal learning”,ACMJournals,Washington,USA,Febuary 2012.

[13] By Tobias Langlotz and ThanhNguyen,"Next generation AR Browsers:- Rich seamless \& adaptive”, IEEE, Vol. 102, Number 2, Febuary 2014.D.O.I:10.1109IJPROC201132294255.

[14] Mark Billinghurst and Adraib Clark,” A Survey of Augmented Reality Foundation and trends in Human Computer Interaction, Vol.8, No.28, 2014.

[15] Luciene Chagas De oliveria and AlcimarBarbojaSoares,"Mobile Augmented Reality enhances Indvor Navigation for Wheel chair users", Research on Biomedical Engineering.

[16] Xiangyu Wang and Henyi Jen, "Designing Virtual construction workside layout in real environment via Augmented Reality”, University of Sydney, Australia, US.

[17] Andrew I. Comport and Muriel Pressigout,” Real time Markless Tracking for Augmented Reality :- The virtual visual serving Framework”, IEEE Transactions on visualization and Computer Graphics,Vol 12, Number 4, July- Aug 2006.

[18] Mei Shiang Cheah and Phaik Ean Wong, “Augmented Reality - A Review on its issues and applications in teaching and learning”, International Journal of Computer and Information Technology, Vol.3, Issue 2, March 2014. 